\title{
Radial keratotomy associated endothelial degeneration
}

This article was published in the following Dove Press journal:

Clinical Ophthalmology

I February 2012

Number of times this article has been viewed

\section{Majid Moshirfar Andrew Ollerton Rodmehr T Semnani Maylon Hsu}

John A Moran Eye Center, Department of Ophthalmology and Visual Sciences, University of Utah, Salt Lake City, UT, USA
Correspondence: Majid Moshirfar Department of Ophthalmology and Visual Sciences, John A Moran Eye Center, University of Utah 6360 S 3000 E \# 200, Salt Lake City, UT 84 I II-6925 USA

Tel + I 80I 5853937

Fax + I 80I 58I 3357

Email majid.moshirfar@hsc.utah.edu
Purpose: To describe the presentation and clinical course of eyes with a history of radial keratotomy (RK) and varying degrees of endothelial degeneration.

Methods: Retrospective case series were used.

Results: Thirteen eyes (seven patients) were identified with clinical findings of significant guttata and a prior history of RK. The mean age of presentation for cornea evaluation was 54.3 years (range: $38-72$ years), averaging 18.7 years (range: $11-33$ years) after RK. The presentation of guttata varied in degree from moderate to severe. Best corrected visual acuity (BCVA) ranged from 20/25 to 20/80. All patients had a history of bilateral RK, except one patient who did not develop any guttata in the eye without prior RK. No patients reported a family history of Fuch's Dystrophy. One patient underwent a penetrating keratoplasty in one eye and a Descemet's stripping automated endothelial keratoplasty (DSAEK) in the other eye.

Conclusions: RK may induce a spectrum of endothelial degeneration. In elderly patients, the findings of guttata may signify comorbid Fuch's dystrophy in which RK incisions could potentially hasten endothelial decomposition. In these select patients with stable cornea topography and prior RK, DSAEK may successfully treat RK endothelial degeneration.

Keywords: radial keratotomy, RK, Descemet's stripping automated endothelial keratoplasty, DSAEK, guttata, endothelial degeneration, Fuch's dystrophy

\section{Introduction}

Radial keratotomy (RK) flattens the central cornea by creating radial incisions to treat myopia. Combined with arcuate keratotomy (AK), astigmatism can also be decreased. ${ }^{1}$ By the late 1990s, excimer laser ablation surgery soon replaced RK due to improved predictability and stability compared to the hyperopic and sometimes myopic refractive shift observed over time with RK. ${ }^{2}$ In addition, complications related to RK have been described including: keractectasia, ${ }^{3}$ corneal perforation, ${ }^{4}$ irregular astigmatism, ${ }^{1}$ and fluctuating vision. ${ }^{5}$

Although endothelial loss has been reported after RK, ${ }^{6,7}$ some studies suggest that the rate of endothelial loss stabilizes over time. ${ }^{8,9}$ We report seven cases (13 eyes) with a previous history of RK presenting with various degrees of guttata and endothelial dysfunction. Included are the outcomes of the first reported Descemet's stripping automated endothelial keratoplasty (DSAEK) in a patient with prior RK and guttata, which are compared to the fellow eye which underwent a penetrating keratoplasty (PKP). 


\section{Methods}

Using departmental database records, seven patients with a history of RK and the presence of guttata on exam were identified. All patients were referred for cornea evaluation at the John A Moran Eye Center, University of Utah between 2006 and 2011. Medical records were reviewed retrospectively documenting ocular, surgical, and family history, exam findings, and clinical course.

\section{Results}

The mean age of presentation for cornea evaluation was 54.3 years (range: $38-72$ years). The mean age at which patients had RK surgery was at 35.6 years old (range 21-55 years), with an average of 18.7 years (range: 11-33 years) prior to cornea consultation (Table 1). All patients had significant guttata noted on slit lamp exam (Figure 1). The depth of RK incisions varied, but no signs of perforations were noted. The presentation of guttata ranged from moderate to severe, with varying levels of endothelial cell counts and polymegathism. Best corrected visual acuity (BCVA) ranged from 20/25 to 20/80. Only one patient (Case 1) underwent cornea transplantations in both eyes. All patients had a history of bilateral RK, except Case 2 in which the eye with no prior RK showed no signs of guttata. No patients reported a family history of Fuch's dystrophy (Table 1). Cases 1-3 are described in detail below.

\section{Case I}

A 57-year-old white woman presented with a BCVA of $20 / 40$ and 20/70, with spectacle correction or manifest refraction $(\mathrm{MR})(-2.50+3.75 \times 5 ;-1.50+0.75 \times 25)$ in the right and left eyes respectively. The patient had previous RK surgery 18 years prior. Slit lamp exam revealed 16 RK incisions in both eyes, with two superior AK incisions and one inferior $\mathrm{AK}$ incision in the right eye, and two AK incisions in the left eye. The patient had a history of Sjogren's syndrome and was intolerant to contact lenses. Confluent diffuse guttata were present in both corneas with minimal nuclear sclerosis of the lenses. Specular microscopy (Noncon Robo, Konan Medical, Irvine, CA) showed endothelial cell counts of 760 and 772 cells per $\mathrm{mm}^{2}$ in the right and left eyes respectively. Ultrasound pachymetry measured central corneal thickness (CCT) of $635 \mu \mathrm{m}$ in the right and $630 \mu \mathrm{m}$ in the left eyes. Topography (Humphrey Atlas, Carl Zeiss, Jena, Germany) revealed irregular astigmatism, greater in the left than right eye.

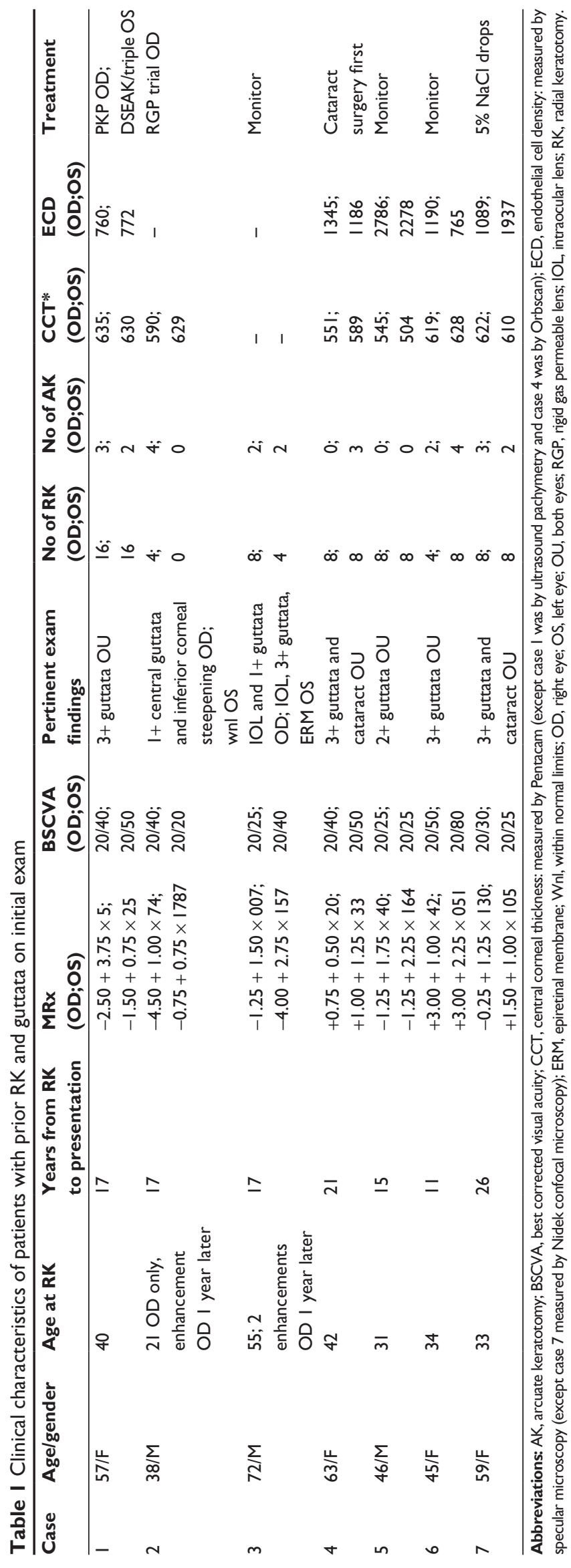




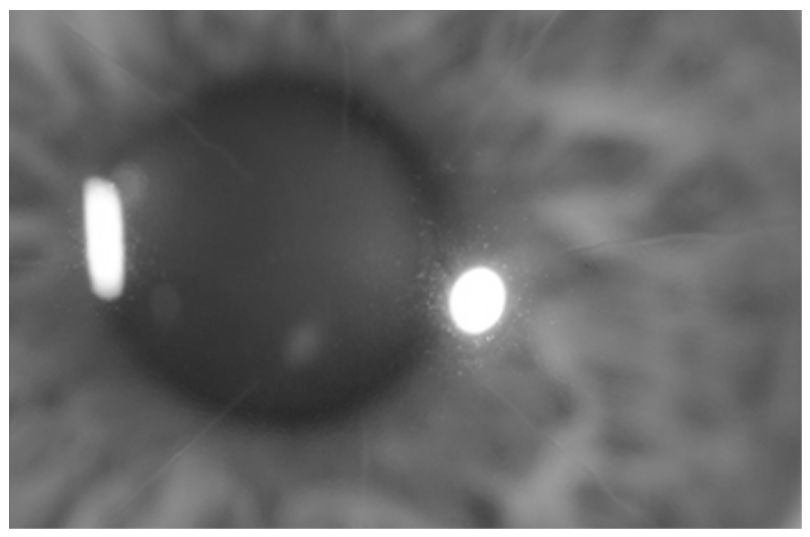

Figure I Slit lamp photo of Case 5 showing RK incisions and moderate central guttata. Abbreviation: RK, radial keratotomy.

Because of a progressive decrease in vision, a PKP was performed in the left eye one year later. Histopathology of the right cornea (Figure 2) showed RK incisions of varying depths with epithelial plugs and guttata. The surgery and clinical course was uneventful. After 18 months of astigmatism management with selective suture removal, BCVA in the left eye was $20 / 30$ with spectacle correction of $-5.25+3.25 \times 145$. BCVA of the right eye had worsened to $20 / 100$, with increasing cataract formation. Right eye simulated keratometry (K) readings (Atlas) were 33.25 diopters (D) at 102 degrees and $38.87 \mathrm{D}$ at 12 degrees showing a stable asymmetric bow-tie with a skewed radial axis pattern on topography.

With consideration of the long postoperative course after PKP in the left eye, increasing cataract, and the relatively stable topography, a DSAEK triple procedure was performed in the right eye. After phacoemulsification of the cataract, and placement of intraocular lens in the capsular bag, the

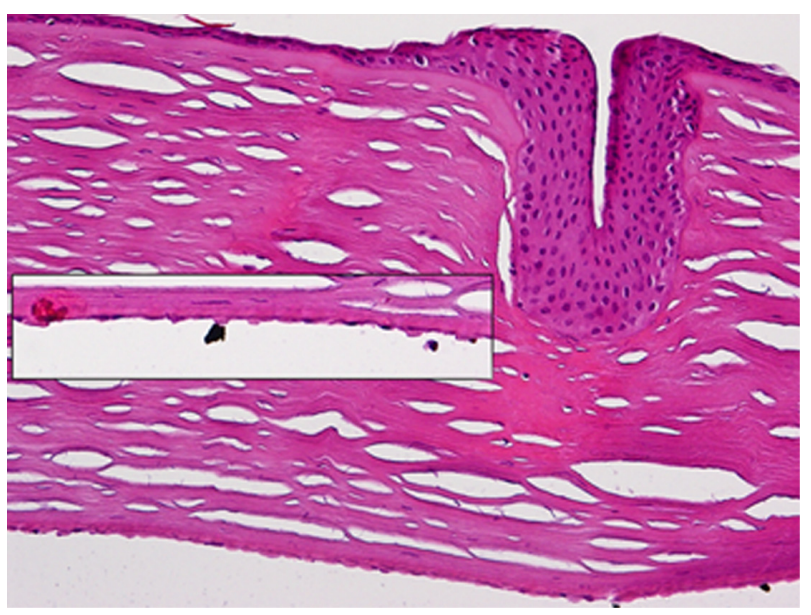

Figure 2 Hematoxylin and eosin stain at 40x magnification of Case I left cornea, showing RK incisions with an epithelial plug and a thickened Descemet's membrane with guttata (insert).

Abbreviation: RK, radial keratotomy
Descemet's membrane was stripped with a reverse sinsky hook. Five peripheral radial venting incisions were created avoiding prior RK and AK incisions. Using a Busin glide (Moria USA, Doylestown, Pennsylvania) an $8.25 \mathrm{~mm}$ posterior donor lenticule was pulled into the anterior chamber using retinal forceps. A full air bubble was left to tamponade the graft for 15 minutes and interface fluid was removed through the venting incisions. The patient had an uncomplicated postoperative course. Prednisolone acetate $1 \%$ was tapered from four times a day to once a day over 6 months, and then gradually to two times per week. Three months after DSAEK, slit lamp exam showed a clear, centered graft, without signs of rejection (Figure 3). BCVA was 20/30 with a MR of $-1.75+7.25 \times 31$. Simulated K readings and topographic pattern remained stable at the 3 months and 1 year visits.

Three years after right eye DSAEK and 4 years after left eye PKP, BCVA was 20/50 and 20/40 in the right and left eyes respectively with MR $(-3.75+6.00 \times 42 ;-6.25+3.00 \times 172)$. Pentacam topography (Oculus Inc, Wetzlar, Germany) revealed a similar pattern of irregular astigmatism of the right eye compared to preoperative topography, with equivalent $\mathrm{K}$ readings at the $4.3 \mathrm{~mm}$ zone of $34.4 \mathrm{D}$ at 122.5 degrees and $37.9 \mathrm{D}$ at 32.5 degrees (Figure 4). Vision fluctuated over the years in both eyes with BCVA ranging from 20/30 to 20/60. There was no significant change in MR after one year from DSAEK surgery. Vision fluctuation was partially due to ocular surface dryness, for which the patient was maintained on cyclosporine $0.05 \%$ topical drops twice daily, cevimeline three times a day, and artificial tears four times per day.

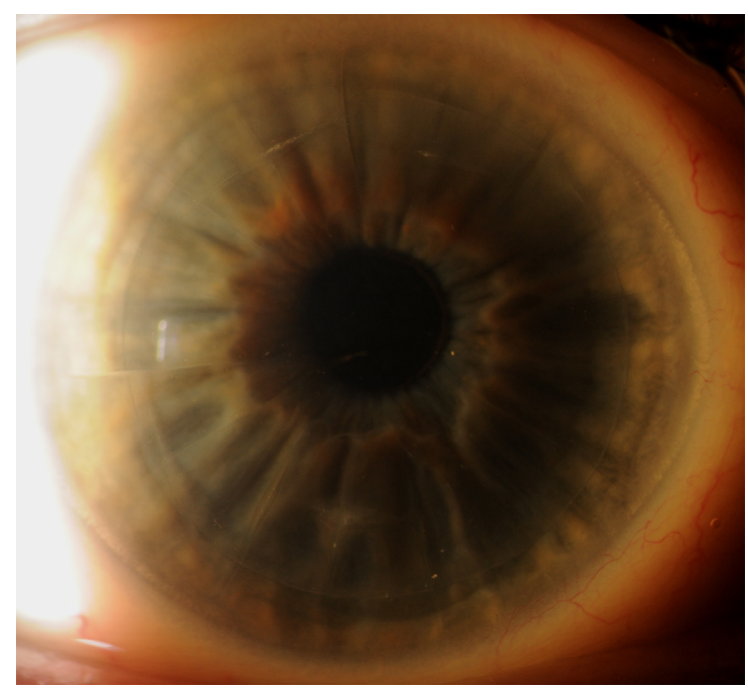

Figure 3 Slit lamp photo of Case I right eye, showing clear cornea with DSAEK graft and prior RK incisions.

Abbreviations: DSAEK, Descemet's stripping automated endothelial keratoplasty; RK, radial keratotomy. 


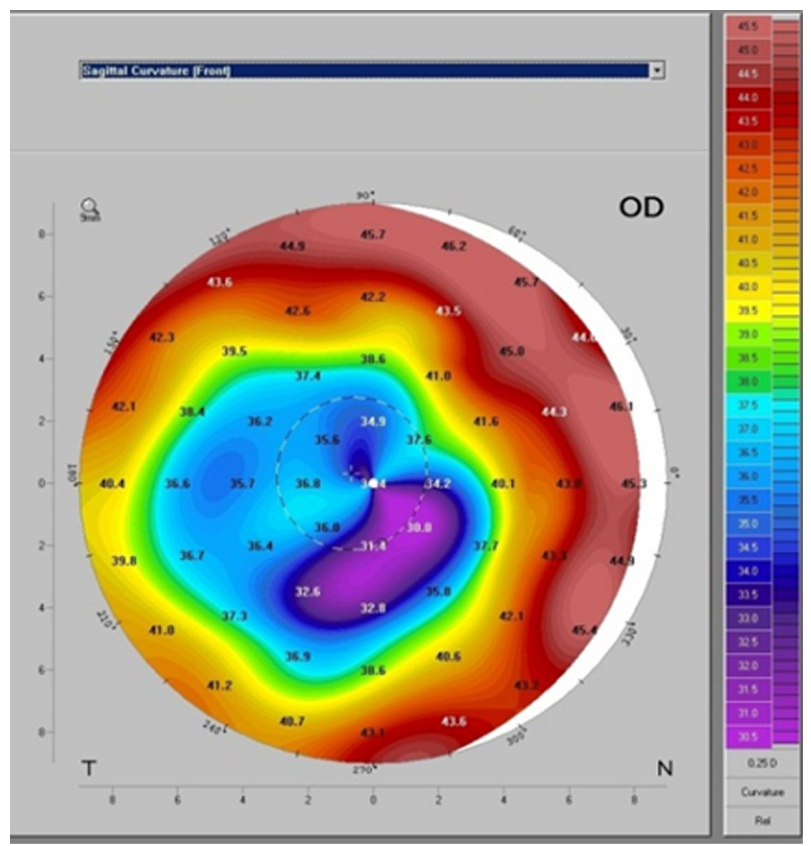

Figure 4 Pentacam sagittal topography map of Case I right eye, 3 years after DSAEK, showing irregular astigmatism from prior radial keratotomy. Abbreviation: DSAEK, Descemet's stripping automated endothelial keratoplasty.

\section{Case 2}

A 38-year-old white male presented with blurry vision in the right eye. BCVA was $20 / 40$ and 20/20 with MR $(-4.25+1.00 \times 74 ;-0.75+0.75 \times 178)$ in the right and left eyes respectively. Seventeen years prior, the patient had prior RK surgery in the right eye only with a RK enhancement one year later. The patient had a past ocular history (one year prior) significant for iritis in the right eye. Slit lamp exam showed central 1+ guttata in the right eye with four RK incisions and four AK incisions, and a normal exam in the left eye. Trace pigment was observed on the anterior capsule with no anterior chamber reaction or keratic precipitates. CCT was $590 \mu \mathrm{m}$ in the right eye and $629 \mu \mathrm{m}$ in the left eye. Pentacam topography showed irregular astigmatism with inferior steepening in the right eye only. Due to the moderate degree of guttata, the plan was to monitor the patient. A rigid gas permeable contact lens was recommended for treatment of the irregular astigmatism.

\section{Case 3}

A 72-year-old white man with an extensive past ocular history was referred for cornea evaluation due to significant guttata. At the age of 55 the patient had RK surgery in both eyes, with two RK enhancements performed on the right eye one year later. On presentation, BCVA was 20/25 in the right eye and 20/30 in the left eye with spectacle correction $(-1.2+1.5 \times 007 ;-4.00+2.75 \times 157)$. Slit lamp exam showed eight RK incisions with two AK incisions in the right eye, and four RK and two AK incisions in the left eye. There was $1+$ guttata in the right cornea and $3+$ guttata in the left cornea.

The patient had cataract surgery 3 years prior, with a history of endophthalmitis in the left eye treated with pars plana vitrectomy. He developed complications of cystoid macular edema and ocular hypertension, which both improved with topical medication. The patient was intentionally made myopic in the left eye after cataract surgery for monovision correction. Although the right eye had more RK incisions than the left, the left eye had a more complicated postoperative course after cataract surgery, which likely increased the amount of endothelial damage. This patient is the oldest patient in the case series. It is unknown when guttata first developed. Because of the relatively good visual acuity, the plan was made to monitor the patient.

\section{Discussion}

It is estimated that several hundred thousand RK procedures were performed annually to treat myopia, in the late 1980's and early 1990 's. ${ }^{1,2}$ PKP or deep anterior lamellar keratoplasty is often required to treat the RK induced irregular astigmatism or keratoectasia when uncorrectable with contact lenses. The present case series reports the association between guttata with endothelial degeneration and RK, in which one eye was treated successfully with a DSAEK. To the best of our knowledge, this is the first reported DSAEK in an eye with RK endothelial degeneration (RKED).

In the 1980's and 1990's, several studies analyzed the significance between RK and endothelial cell loss. One of the earliest forms of RK developed by Sato in the 1940's utilized both anterior and posterior incisions. Ten years after surgery, 60 of 80 eyes developed bullous keratopathy. ${ }^{7}$ Chiba et al reported a post-RK endothelial cell loss of $14.1 \%$ with significant pleomorphism associated with microperforation and a smaller central clear zone of treatment, 6 to 30 months after surgery. ${ }^{6}$ In animal models, no difference between the reported $14 \%-15 \%$ endothelial cell loss was seen in eight versus 16 incision RK at 6 months. ${ }^{10}$

With longer follow up, early studies suggested a nonprogressive acute traumatic endothelial cell loss that stabilized over time. ${ }^{8,9,11}$ In a study of 52 eyes which underwent RK, Hoffer et al reported $10 \%$ endothelial cell loss 3 months after the 16-incision procedure, with no difference in the ten eyes with microperforations. ${ }^{12}$ In a follow up study, the authors reported endothelial cell counts after 2 years increased by $2 \% .{ }^{1}$ [9] Mac Rae et al similarly reported a 3.3\% rate of 
endothelial cell loss 1 year after $\mathrm{RK},{ }^{13}$ which decreased to $0.4 \%$ per year after an average of 7 years follow up. ${ }^{8}$ In monkey eyes, Dunn et al showed a 13\% loss 1 month after RK, with stabilization of polymegathism and no progressive endothelial cell loss 4 years later. ${ }^{14}$ In analyzing endothelial cell differences in RK patients and age matched controls, Zhao et al reported no difference was seen in endothelial cell density, however subtle morphologic changes were noted in the RK group with a follow up of $11-18$ years. ${ }^{15}$ Although these studies show a trend of stabilization, the effects of RK 20 to 30 years after surgery is unknown. The 13 eyes presented with RKED range in longer follow up from 11 to 26 years after RK.

Primary central guttata develop from dystrophic endothelium representing focal thickening of Descemet's membrane. ${ }^{16}$ They pose little clinical significance unless they become confluent and can lead to endothelial dysfunction. Population studies have estimated cornea guttata of patients older than $40-55$ years to be $3.7 \%-11 \%,{ }^{17-19}$ increasing with age $^{20}$ with a higher prevalence in females. ${ }^{17,21}$ Most patients who had RK were under 40 years of age with presumably healthy endothelium. ${ }^{2}$ Salz reported a larger overcorrection and a 50\% endothelial cell loss 4 years after RK in a 68-yearold likely due to age related preoperative endothelial dysfunction which rapidly decompensated after RK surgery. ${ }^{22}$

As many of the RK patients become older, comorbid guttata such as seen in Fuch's dystrophy may also increase. However, the cases presented included three patients (Cases 2, 5, and 6) who were under the age of 50 with RKED. No patients reported a family history of Fuch's dystrophy, although no family members were examined to confirm these findings. One patient had unilateral guttata in the eye, which underwent RK, with completely normal endothelium in the contralateral eye which had no history of RK. The RK eye also had a remote history of iritis. Secondary guttata may occur after trauma, uveitis, breaks in Descemet's membrane, posterior keratoconus. ${ }^{23}$ Transient guttata (termed pseudoguttata) have been reported after episodes of iritis or cornea inflammation clinically disappearing with resolution of inflammation. ${ }^{16,24}$ As the patient had no signs of anterior chamber or cornea inflammation, these are less likely to be related to the isolated episode of iritis and more likely associated to the history of RK.

The cases presented range in severity of RKED. RK may hasten the presentation of guttata development of endothelial cell compromise in those patients with an underlying predisposition. Additionally, an age related decline in endothelial cell density and function may make older corneas more susceptible to RK-induced trauma over time. The higher number of endothelial cell counts paracentrally and peripherally compared to the central region ${ }^{25}$ supports findings that endothelial precursor cells are concentrated peripherally. ${ }^{26}$ As RK incisions cut radially into the cornea, it is possible the incisions may also disrupt the pattern of endothelial cell migration and stem cell proliferation. RK incisions may induce focal trauma at the time of surgery with persistent ongoing trauma years after surgery. Histopathologic analysis has demonstrated endothelial damage associated with deeper cuts after RK in monkeys. ${ }^{27}$ Posterior Descemet's membrane folds have been observed under RK incisions even without microperforation. ${ }^{27,28}$

These subsets of post-RK patients with guttata may present with cataracts and extra caution should be taken to protect the endothelium during surgery. Diurnal vision fluctuations have been described and are thought to correlate with intraocular pressure or cornea hydration changes of unstable peripheral cornea lamella. ${ }^{5} \mathrm{RK}$ incisions may cause corneal stretching and fluctuations that may add to subsequent and cumulative endothelial injury. ${ }^{27}$ As many RK patients have a history of contact lens use both before and after refractive surgery, contact lens induced polymegathism and pleomorphism may further contribute to endothelial cell loss. ${ }^{29}$

Whether treatment of RKED should be managed with a PKP or DSAEK requires careful evaluation of corneal topography. If significant irregular astigmatism, anterior stromal scarring, or ectasia is present, then a PKP may be required since a DSAEK would not improve any of these anterior cornea pathologies. However, if topography is stable over time as was demonstrated in Case 1, a DSAEK may be a better option due to the faster recovery and decreased risk of PKP intraoperative and postoperative complications. Although vision was 20/30 3 months after DSAEK, the vision continued to fluctuate over the next 3 years due to both comorbid ocular surface dryness and the prior $\mathrm{AK}$ and $\mathrm{RK}$ incisions.

In conclusion, we report the association of prior RK and endothelial degeneration as evidenced by guttata becoming confluent in over half the cases presented. This case series is limited by the retrospective nature, which made it difficult to quantify exact RK incision depth and the inability to follow patients over time from onset of RK. Although not all patients with prior RK will develop signs or symptoms of RKED, those predisposed or perhaps those with deeper RK incisions may present with endothelial damage and decompensation. While some guttata may signify the concurrent development of Fuch's dystrophy, a previous history of RK may induce a 
more rapid decompensation. In select patients, a DSAEK may be a considered as an alternative to PKP for RKED.

\section{Disclosure}

The authors report no conflicts of interest in this work.

\section{References}

1. Radial keratotomy for myopia. American Academy of Ophthalmology. Ophthalmology. 1993;100(7):1103-1115.

2. Waring GO 3rd, Lynn MJ, McDonnell PJ. Results of the prospective evaluation of radial keratotomy (PERK) study 10 years after surgery. Arch Ophthalmol. 1994;112(10):1298-1308.

3. Shaikh S, Shaikh NM, Manche E. Iatrogenic keratoconus as a complication of radial keratotomy. J Cataract Refract Surg. 2002;28(3): 553-555.

4. Karr DJ, Grutzmacher RD, Reeh MJ. Radial keratotomy complicated by sterile keratitis and corneal perforation. Histopathologic case report and review of complications. Ophthalmology. 1985;92(9):1244-1248.

5. Kemp JR, Martinez CE, Klyce SD, et al. Diurnal fluctuations in corneal topography 10 years after radial keratotomy in the Prospective Evaluation of Radial Keratotomy Study. J Cataract Refract Surg. 1999;25(7):904-910.

6. Chiba K, Oak SS, Tsubota K, Laing RA, Goldstein J, Hecht S. Morphometric analysis of corneal endothelium following radial keratotomy. $J$ Cataract Refract Surg. 1987;13(3):263-267.

7. Kanai A, Tanaka M, Ishii R, Nakajima A. Bullous keratopathy after anterior-posterior radial keratotomy for myopia for myopic astigmatism. Am J Ophthalmol. 1982;93(5):600-606.

8. MacRae SM, Rich LF. Long-term effects of radial keratotomy on the corneal endothelium. J Refract Surg. 1998;14(1):49-52.

9. Hoffer KJ, Darin JJ, Pettit TH, Hofbauer JD, Elander R, Levenson JE. Three years experience with radial keratotomy. The UCLA study. Ophthalmology. 1983;90(6):627-636.

10. Jester JV, Steel D, Salz J, et al. Radial keratotomy in non-human primate eyes. Am J Ophthalmol. 1981;92(2):153-171.

11. Tseng SH, Chen FK. Morphological and fluorophotometric analysis of the corneal endothelium after radial keratotomy. Cornea. 1998;17(5): $471-475$.

12. Hoffer KJ, Darin JJ, Pettit TH, Hofbauer JD, Elander R, Levenson JE. UCLA clinical trial of radial keratotomy. Preliminary report. Ophthalmology. 1981;88(8):729-736.

13. MacRae SM, Matsuda M, Rich LF. The effect of radial keratotomy on the corneal endothelium. Am J Ophthalmol. 1985;100(4):538-542.
14. Dunn S, Jester JV, Arthur J, Smith RE. Endothelial cell loss following radial keratotomy in a primate model. Arch Ophthalmol. 1984;102(11): $1666-1670$

15. Zhao L, Wang YL, Liu P, Liu X. Long-term changes of corneal endothelial cells with radial keratotomy. [Zhonghua yan ke za zhi] Chinese Journal of Ophthalmology. 2008;44(6):511-516.

16. Krachmer JH, Schnitzer JI, Fratkin J. Cornea pseudoguttata: a clinical and histopathologic description of endothelial cell edema. Arch Ophthalmol. 1981;99(8):1377-1381.

17. Higa A, Sakai H, Sawaguchi S, et al. Prevalence of and risk factors for cornea guttata in a population-based study in a southwestern island of Japan: the Kumejima study. Arch Ophthalmol. 2011;129(3):332-336.

18. Zoega GM, Fujisawa A, Sasaki H, et al. Prevalence and risk factors for cornea guttata in the Reykjavik eye study. Ophthalmology. 2006; 113(4):565-569.

19. Kitagawa K, Kojima M, Sasaki H, et al. Prevalence of primary cornea guttata and morphology of corneal endothelium in aging Japanese and Singaporean subjects. Ophthalmic Res. 2002;34(3):135-138.

20. Lorenzetti DW, Uotila MH, Parikh N, Kaufman HE. Central cornea guttata. Incidence in the general population. Am J Ophthalmol. 1967;64(6): 1155-1158.

21. Kitagawa K, Fujisawa A, Mizuno T, Sasaki K. Twenty-three cases of primary cornea guttata. Jpn J Ophthalmol. 2001;45(1):93-98.

22. Salz JJ. Multiple complications following radial keratotomy in an elderly patient: a case report. Ophthalmic Surg. 1985;16(9):579-580.

23. Wolter JR, Larson BF. Pathology of cornea guttata. Am J Ophthalmol. 1959;48(1 Pt 2):161-169.

24. Zantos SG, Holden BA. Guttate endothelial changes with anterior eye inflammation. Br J Ophthalmol. 1981;65(2):101-103.

25. Amann J, Holley GP, Lee SB, Edelhauser HF. Increased endothelial cell density in the paracentral and peripheral regions of the human cornea. Am J Ophthalmol. 2003;135(5):584-590.

26. Yamagami S, Yokoo S, Mimura T, Takato T, Araie M, Amano S. Distribution of precursors in human corneal stromal cells and endothelial cells. Ophthalmology. 2007;114(3):433-439.

27. Yamaguchi T, Kaufman HE, Fukushima A, Safir A, Asbell PA. Histologic and electron microscopic assessment of endothelial damage produced by anterior radial keratotomy in the monkey cornea. $\mathrm{Am} \mathrm{J}$ Ophthalmol. 1981;92(3):313-327.

28. Stainer GA, Shaw EL, Binder PS, Zavala EY, Akers P. Histopathology of a case of radial keratotomy. Archives of ophthalmology. 1982;100(9): 1473-1477.

29. MacRae SM, Matsuda M, Shellans S. Corneal endothelial changes associated with contact lens wear. CLAO J. 1989;15(1):82-87.
Clinical Ophthalmology

\section{Publish your work in this journal}

Clinical Ophthalmology is an international, peer-reviewed journal covering all subspecialties within ophthalmology. Key topics include: Optometry; Visual science; Pharmacology and drug therapy in eye diseases; Basic Sciences; Primary and Secondary eye care; Patient Safety and Quality of Care Improvements. This journal is indexed on Submit your manuscript here: http://www.dovepress.com/clinical-ophthalmology-journal

\section{Dovepress}

PubMed Central and CAS, and is the official journal of The Society of Clinical Ophthalmology (SCO). The manuscript management system is completely online and includes a very quick and fair peer-review system, which is all easy to use. Visit http://www.dovepress.com/ testimonials.php to read real quotes from published authors. 